\title{
Assessment of a pilot system for seawater desalination based on vacuum multi-effect membrane distillation with enhanced heat recovery
}

\author{
J.A. Andrés-Mañas ${ }^{\mathrm{a}}$, A. Ruiz-Aguirre ${ }^{\mathrm{b}, \mathrm{c}}$, F.G. Acién ${ }^{\mathrm{b}}$, G. Zaragoza ${ }^{\mathrm{a}, *}$ \\ a CIEMAT - Plataforma Solar de Almeria, Ctra. De Senés s/n, 04200 Tabernas, Almeria, Spain \\ b Universidad de Almeria - CIESOL, Ctra. Sacramento s/n, 04120 La Cañada de San Urbano, Almeria, Spain \\ ${ }^{\mathrm{c}}$ Dipartimento dell'Innovazione Industriale e Digitale (DIID), Ingegneria Chimica, Gestionale, Informatica, Meccanica, Università di Palermo (UNIPA), viale delle Scienze \\ Ed.6, 90128 Palermo, Italy
}

\section{A R T I C L E I N F O}

\section{Keywords:}

Vacuum-multi-effect membrane distillation

Seawater desalination

Energy efficiency

Heat recovery

Pilot-scale evaluation

\begin{abstract}
A B S T R A C T
This work presents the evaluation of an innovative system based on vacuum multi-effect membrane distillation modules (V-MEMD) for seawater desalination at pilot scale. This four-effect unit introduces a remarkable modification from previous V-MEMD systems, consisting of the use of the seawater feed flow as cooling in the condenser, rather than a separate circuit. Preheating the feed in the condenser improved heat efficiency (maximum gained output ratio obtained for seawater was 3.2). Maximum distillate fluxes reached $8.51 \mathrm{~h}^{-1} \mathrm{~m}^{-2}$ for hot feed temperature $75^{\circ} \mathrm{C}$ and feed flow rate $1501 \mathrm{~h}^{-1}$. Increasing both parameters to raise the productivity was hindered by the inability of the condenser to cope with all the steam generated in previous effects, resulting in overheating and overpressure. Furthermore, a loss of $40 \%$ of distillate production was measured due to the increase of seawater cooling temperature by $8{ }^{\circ} \mathrm{C}$ along the year. Finally, it was observed that scaling reduced distillate production up to $50 \%$. Acid cleaning successfully removed scaling and restored the performance. Subsequently, the use of an antiscalant as a pre-treatment was sufficient to prevent it.
\end{abstract}

\section{Introduction}

Membrane distillation (MD) is a non-isothermal membrane separation technique $[1,2]$ with a promising application niche in processes in which low temperature heat sources are applied to the desalination of seawater or high salinity feeds [3, 4]. MD units are usually modular and scalable, and are made of cheaper corrosion-free materials, so the technology can be an alternative to current thermal desalination techniques implemented at large scale. However, MD has not reached yet a full commercial breakthrough. The need to develop prototypes at commercial scale to assess its true techno-economic potential and to comprehend the unforeseeable problems has been pointed out recently by many authors [5-8]. One of the main identified barriers is energy consumption $[4,8,9]$. Several efforts have been made to reduce the energy consumption in pilot scale MD applications. The recovery of latent heat of condensation as sensible heat for preheating the feed has been evaluated by coupling modules in series for the treatment of simulated seawater [10,11] and wastewater [12]. This requires external devices, which can be avoided by designing internal heat recovery in one single module. This has been proposed using hollow fibre membranes and flat-sheet membranes in spiral-wound configuration. In the case of hollow fibre, only small-scale modules have been tested [13-15]. In the case of spiral-wound, extensive evaluation at pilot scale has been carried out, both in simulated conditions [16-19] and in demonstration plants for producing potable water in remote areas [20, 21]. Currently, multi-channel spiral-wound modules working in air-gap (AGMD) configuration are the ones with the best internal heat efficiency demonstrated at pilot scale, reaching values of the specific thermal energy consumption below $100 \mathrm{kWh} \mathrm{m}^{-3}$ for seawater, equivalent to gained output ratio (GOR) larger than 6 [18, 19]. In permeate-gap (PGMD) and AGMD systems, non-condensable gases can decrease the vapour flux in the pores, so they must be eliminated from the feed by deaeration, with the subsequent energy loss [22]. This is avoided in vacuum membrane distillation (VMD). The application of vacuum in the permeate side of the membrane was considered in first studies of MD as a way to facilitate the diffusion of the water vapour inside the pores, and at the same time decreasing the heat conducted through the membrane [23]. Thus, VMD has the highest potential for heat efficiency [24]. However, in VMD condensation occurs at the saturation temperature corresponding to the reduced pressure, limiting the temperature that the cold feed can reach with internal heat recovery, so multi-stage configurations coupling several VMD modules

\footnotetext{
* Corresponding author.

E-mail address: guillermo.zaragoza@psa.es (G. Zaragoza).
} 


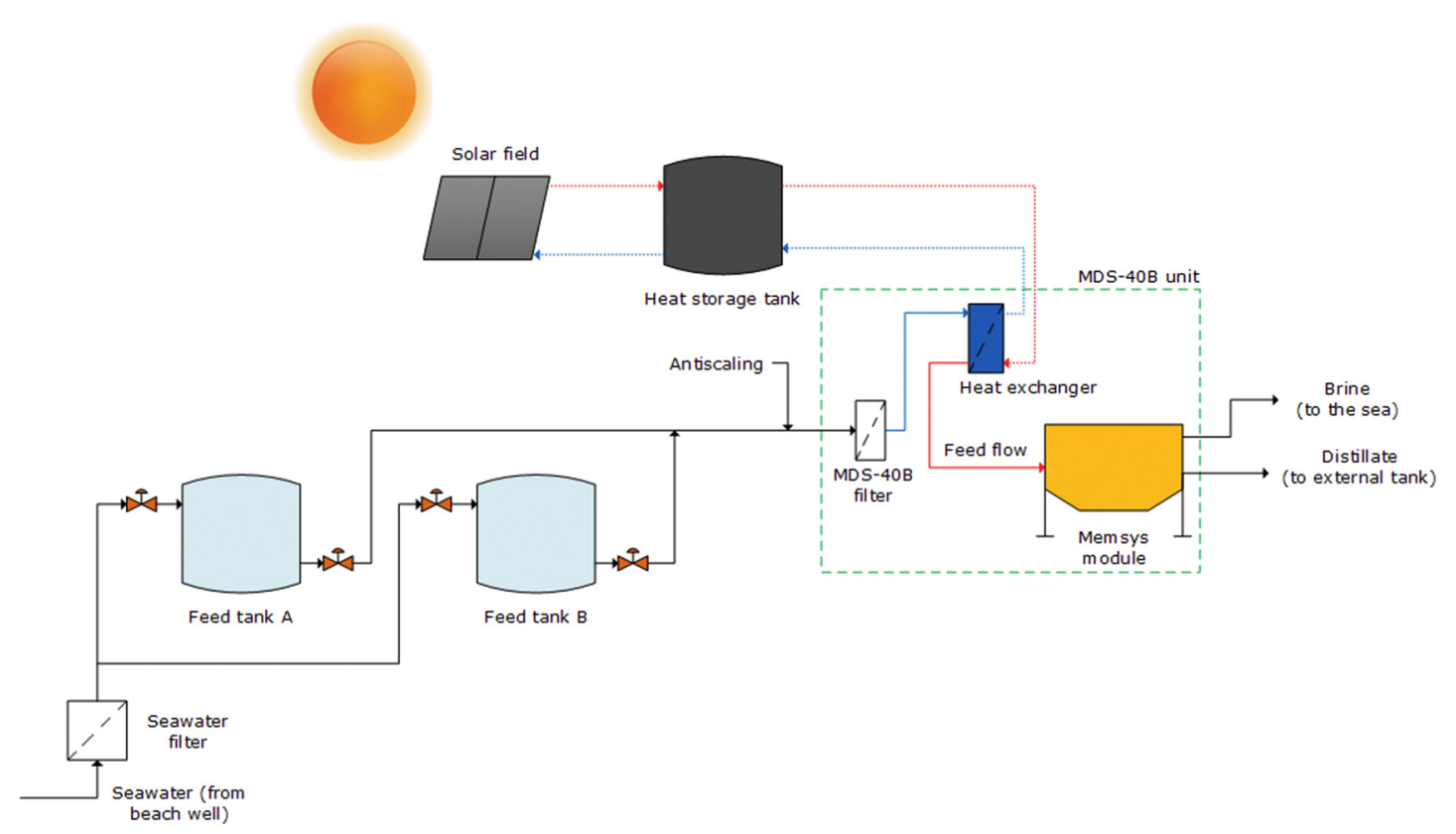

Fig. 1. Diagram showing the main components of the seawater desalination pilot plant.

are required for better heat efficiency [25]. Several multi-stage arrangements for VMD with heat recovery have been simulated. A 24stage model has been developed by Kim et al. [26] considering hollow fibre configuration and different number of heat recovery units. Other simulation study performed by Chung et al. [27] has been focused on the influence of the number and area of the stages in the energy efficiency of a multi-stage VMD system. Finally, Zhang et al. [28] have performed a thermal analysis of two similar theoretical arrangements with different heat delivery. The only pilot experiment was by Xing et al. [29], testing a three-stage hollow-fibre VMD system with simulated seawater and reaching values of GOR of 2.76.

In all those systems the latent heat of condensation is recovered as sensible heat, thus an increase of heat recovery is associated with a decrease of transmembrane temperature difference and subsequently of the flux $[18,30]$. In multi-effect configurations, the latent heat of condensation of the vapour is used to evaporate more feed water in subsequent effects, not only for preheating the feed. As in the case of multi-effect distillation (MED), this means an increase in both productivity and heat efficiency, and therefore the chance of concentrating water sources even more. This concept is exploited in the vacuum multi-effect (V-MEMD) technology, patented by W. Heinzl and commercialized by memsys, who launched their novel plate-and-frame VMEMD modules in 2010 [31]. Their particular configuration not only avoids deaeration, but also recovers heat for further evaporation in different effects, improving the energy efficiency [32]. A four-effect VMEMD module has been evaluated with low salt water $\left(2.3 \mathrm{mS} \mathrm{cm}^{-1}\right)$ as feed [33], and with real seawater [34]. Distillate fluxes were 8.1 and $4.81 \mathrm{~h}^{-1} \mathrm{~m}^{-2}$, respectively, but no information was given on energy efficiency. Some studies have been reported on the operation with high salinity, mostly focused on productivity. Aqueous sodium chloride solutions have shown good performance with concentrations up to $3 \mathrm{M}$ in a lab-scale single-effect module [35]. The effluent with concentration $70 \mathrm{gl}^{-1}$ coming from a thermal desalination plant has been treated with the same V-MEMD module, obtaining $4.51 \mathrm{~h}^{-1} \mathrm{~m}^{-2}$ of distillate [34]. In another study, a solution with up to $22.0 \mathrm{wt} \%$ of sodium chloride (very close to saturation) has been desalinated during six months using a two-effect V-MEMD module, obtaining a distillate flux of $7.01 \mathrm{~h}^{-1} \mathrm{~m}^{-2}$ [36].

There are not many studies in the literature of V-MEMD dealing with energy use. With a four-effect V-MEMD module, values of GOR below 2 and distillate fluxes up to $1.01 \mathrm{~h}^{-1} \mathrm{~m}^{-2}$ have been obtained in the treatment of $40 \mathrm{wt} \%$ calcium chloride solutions for their use as liquid desiccant [37]. A similar V-MEMD system was used in the treatment of up to $22 \mathrm{wt} \%$ lithium chloride solutions for the same purpose. GOR was 0.63 and distillate flux was $0.71 \mathrm{~h}^{-1} \mathrm{~m}^{-2}$, because of the low temperature of the heat source and the high boiling point elevation of the concentrated solution [38]. GOR values up to 2.79 and distillate flux of $3.01 \mathrm{~h}^{-1} \mathrm{~m}^{-2}$ have been reported for a four-effect module using real seawater as feed [32]. In another performance study, GOR values between 1.0 and 2.2 and distillate fluxes up to $7.71 \mathrm{~h}^{-1} \mathrm{~m}^{-2}$ have been reported for a four-effect V-MEMD module with prepared feed brackish water [39]. A similar module was used for the concentration of inland saline groundwater from 6.3 to $10.2 \mathrm{wt} \%$ as a previous step for a humidification-dehumidification crystallizer. The module yielded $5.01 \mathrm{~h}^{-1} \mathrm{~m}^{-2}$ with a GOR of 3 [40]. Finally, a six-effect V-MEMD module has been evaluated in laboratory studies showing GOR values between 3.2 and 3.82 for seawater feed [41], and values of the specific thermal energy consumption lower than $200 \mathrm{kWh} / \mathrm{m}^{3}$ (corresponding to GOR values slightly above 4) have been reported for seawater desalination with another six-effect V-MEMD module [42].

In this paper, the evaluation of a four-effect V-MEMD pilot unit using seawater as feed is described, focused on productivity and heat efficiency. This V-MEMD unit incorporates a remarkable modification from the previous V-MEMD systems mentioned above, consisting of the use of the seawater feed flow as cooling in the condenser rather than a separate circuit. This way, the feed can be preheated with latent heat of condensation that otherwise would be lost. This additional heat recovery concept has been evaluated at pilot scale for the first time in this V-MEMD unit. Tests performed during different periods of the year show the behaviour of the system along the different weather conditions. Also, the long experimental campaign allows to analyse the effect of scaling, the cleaning of the membranes and the use of pre-treatment.

\section{Materials and methods}

The pilot plant presented in this work was designed for the desalination of seawater using MD technology and solar energy as thermal source. It is installed over the flat roof of a building at the University of Almeria, $150 \mathrm{~m}$ away from the seashore. The desalination system has three main components: the seawater intake, the solar collection 
Table 1

Ionic composition of the Mediterranean seawater used in this work.

\begin{tabular}{ll}
\hline & Mass percentage [\%] \\
\hline Cations & \\
$\mathrm{Na}^{+}$ & 33.8 \\
$\mathrm{Ca}^{2+}$ & 2.1 \\
$\mathrm{~K}^{+}$ & 1.0 \\
$\mathrm{Mg}^{2+}$ & 1.0 \\
$\mathrm{Others}^{2+}, \mathrm{Fe}^{2+}, \mathrm{Fe}^{3+}, \mathrm{Cu}^{2+}$, etc. $)$ & Traces \\
$\mathrm{Anions}^{-}$ & \\
$\mathrm{Cl}^{-}$ & \\
$\mathrm{SO}_{4}{ }^{2-}$ & 55.8 \\
$\mathrm{HCO}_{3}{ }^{-}$ & 5.2 \\
$\mathrm{Others}^{2-} \mathrm{CO}_{3}{ }^{2-}, \mathrm{NO}_{3}{ }^{2-}, \mathrm{HPO}_{4}{ }^{2-}$, etc. $)$ & 1.0 \\
& Traces \\
\hline
\end{tabular}

system, and the MD device, called MDS-40B (Fig. 1). They are described separately below. Since the module uses seawater in the condenser, electricity is required only for running pumps and regulation valves, as well as for the control system. The manufacturers of the MDS-40B unit (Aquaver BV, Netherlands) determined an electrical power requirement of $300 \mathrm{~W}$ for this unit. This amount of electricity could be supplied with state of the art solar photovoltaic panels using batteries to guarantee constant power. However, the experiments shown in this paper were all performed using the available electric grid for simplicity, since the main energy consumption of the MD system is thermal energy.

\subsection{Experimental setup}

\subsubsection{Seawater intake}

The system utilises real seawater coming from an $80 \mathrm{~m}$ deep beach well dug $20 \mathrm{~m}$ away from the seashore. The ground acts as a natural filter and allows getting quite clean seawater from the well, although with a bit less electrical conductivity than in the sea $\left(37-40 \mathrm{mS} \mathrm{cm}^{-1}\right)$. The typical composition of the Mediterranean seawater used in this work is indicated in Table 1. This is probably due to underground water filtrations. The water from the well is driven to a buried tank for settling, which is connected to a distribution system that feeds two 10001 containers (AquaTonne, Schütz $\mathrm{GmbH}$, Germany). The only filtration system other than the natural pre-filtration of the beach well is a $50-\mu \mathrm{m}$ cartridge before filling the tanks. The filter has processed more than $100 \mathrm{~m}^{3}$ of feed water without cleaning, showing the effectivity of the beach well for filtration. The containers are permanently refilled and have a buoy valve for cutting the feed flow automatically before it spills. Both are painted with a white anti-thermal coating to avoid an increase in the feed water temperature due to solar radiation.

\subsubsection{Solar collection system}

The solar field is made up of 15 flat-plate collectors (Euro L20 AR, by Wagner \& Co., Germany), tilted $45^{\circ}$, with total aperture area of $35.9 \mathrm{~m}^{2}$, stagnant temperature up to $219^{\circ} \mathrm{C}$, and nominal thermal power up to $17 \mathrm{~kW}_{\text {th }}$ at $90^{\circ} \mathrm{C}$. They are arranged in five racks of three collectors each, fed in reverse return configuration for ensuring that the flow is distributed equitably and the temperature is as uniform as possible. All the circuit is filled with a solution of $30 \mathrm{vol} \%$ of antifreeze (DC20, Wagner \& Co., Germany) in tap water (herein referred to as solar fluid). The solar field is connected to a hydraulic frame, which holds all the flowmeters (Promag 50P40, Endress + Hauser AG, Switzerland) and pumps (Solar 25-120, Grundfos TM, Sweden) in the facility. Thermally insulated copper pipes are used in all the circuits, for avoiding heat losses as much as possible. The use of heat storage in the solar field facilitates providing thermal energy under steadier conditions to the desalination unit. Data acquisition and control of every electronic element is made using a Supervisory Control And Data Acquisition software. The solar field is used to supply heat to the desalination unit, which is the main focus of this paper; analysing or
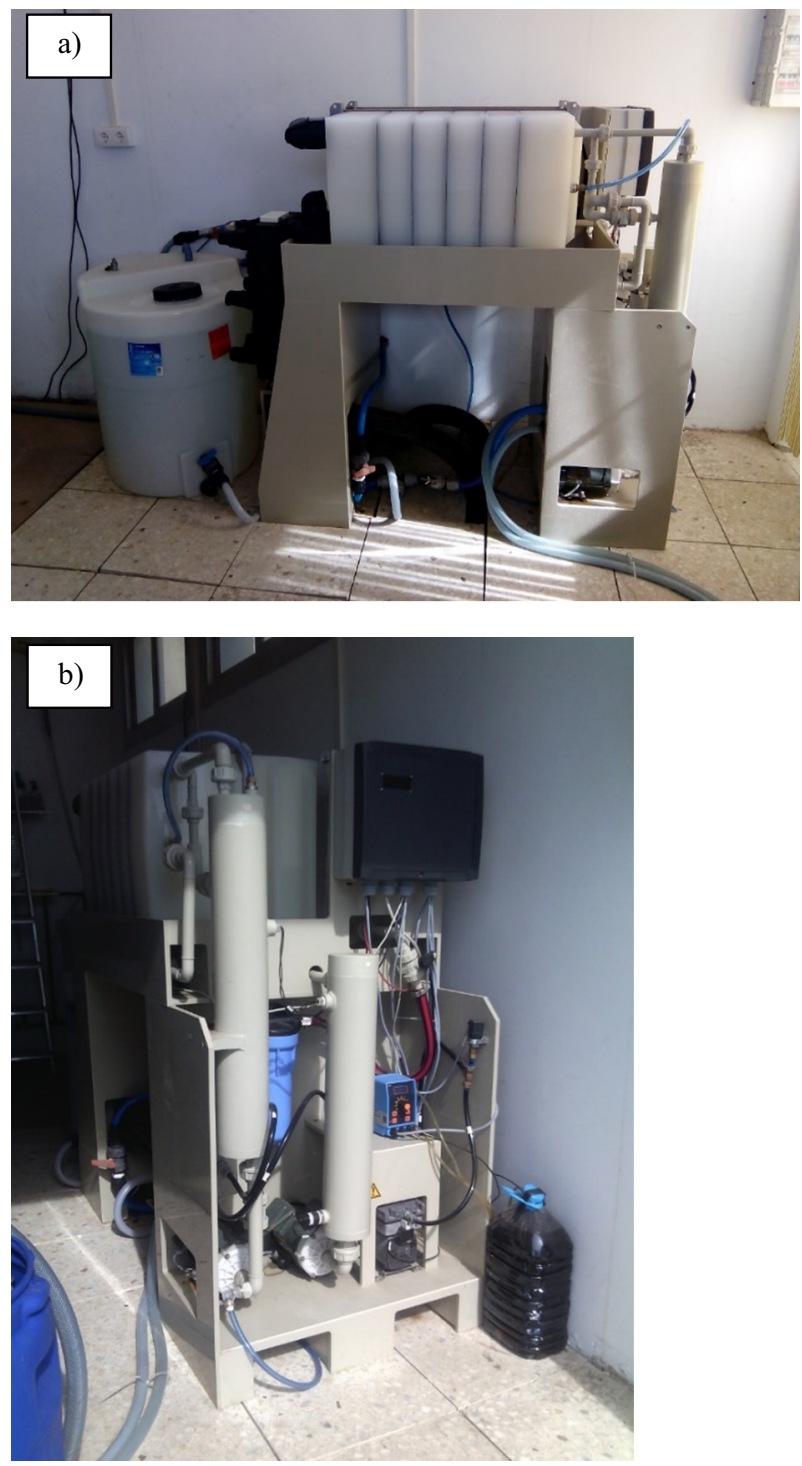

Fig. 2. Aquaver's MDS-40B prototype: a) lateral view, showing the auxiliary distillate tank, and b) front view, showing the brine and distillate vessels of the unit and the control panel.

characterizing its behaviour is not the object of this work.

\subsubsection{V-MEMD desalination system}

The commercial desalination prototype operated in this study is called MDS-40B and was assembled by Aquaver BV (Fig. 2). It uses a novel V-MEMD module developed and build by memsys, which works under vacuum with pressure even lower than 100 mbar (depending on the operating conditions) and with high recovery ratios. The module is made of polypropylene (PP) and has an effective membrane area of $6.4 \mathrm{~m}^{2}$. It is formed by a steam raiser, four desalination effects, and a condenser. All of them are adjusted with silicon gaskets between one and the next, and with four threaded rods and four lateral compressive plates, which keep every effect joined as a whole, thus protecting the membranes against mechanical stress, even in vacuum. Each effect consists of 11 frames, thermo-welded one after the other, alternating polytetrafluoroethylene (PTFE) microporous membranes and PP condensation foils, separated both by a PP spacer, forming a channel between them. The steam raiser is formed by 17 frames with membranes, and the condenser by other 17 frames but only with PP foils. Foils are around $40 \mu \mathrm{m}$ thick [32]. The membranes have a porosity of around $85 \%$ and a mean pore size of $0.2 \mu \mathrm{m}$, the active layer is $20 \mu \mathrm{m}$ thick and 
is supported by a $200 \mu \mathrm{m}$ thick backing [43]. Because of their high hydrophobicity, membranes have low specific heat transfer surface and low heat losses. However, the thermal resistance of the backing or even some system plastic parts is limited, so the maximum working temperature allowed by the unit without operational problems is about $85^{\circ} \mathrm{C}$. The V-MEMD module used in the MDS-40B unit has a further innovative feature: vapour is transported from each successive effect and to the condenser by internal channels, not externally by siphons $[32,33]$. This feature increases the distillate flux and allows a better removal of the non-condensable gases for deaerating the module.

The main innovation in this prototype, however, is that the feed itself is used as cooling source for condensing the vapour produced in the last effect. The seawater passes through the condenser and it is thus preheated by the vapour. Part of that cooling flow is discarded with the brine (typically between 50 and $80 \%$, depending on the operating conditions), while the rest is the real feed entering the steam raiser of the module, after being further heated in a plate and frame heat exchanger to the desired temperature level. The amount of seawater discarded is adjusted by means of two manual valves: V1 placed after the flowmeter and before the heat exchanger, and V2 placed in the rejection line before the brine tank (Fig. 3). Another particular feature of the MDS-40B is that the heat exchanger is connected to the vacuum system and operates in two phases, since liquid feed is evaporated with heat from the solar field. The mix of vapour and liquid is fed into the membranes of the steam raiser. Steam passes through the membranes to the condensing foils of the first effect, and liquid feed continues through the feed channel to the other side of the condensing foils of the first effect, where it evaporates to enter the membranes of the second effect. This way, the steam raiser acts more like a separator of the steam generated in the heat exchanger.

The MDS-40B is operated using a control and data acquisition system, which registers data of pressure inside the condenser (P1), distillate conductivity ( $\mathrm{S} 1$ ), feed flow rate (F1), and feed temperature (T1). The temperatures of seawater entering (Tc) and leaving the condenser (Thx) are also measured, although not registered electronically by the unit. Other values of pressure and temperature inside the module cannot be known due to the absence of sensors in the unit. This should not affect the results, but can hinder the interpretation of the internal physical processes inside the unit. In particular, the lack of measurements of temperature and pressure in each effect does not allow analysing them separately. Nevertheless, the objective of this paper is to evaluate the desalination unit as a whole, and the available measurements are enough for assessing its performance.

\subsection{Experimental procedure}

With the system described in this section, an operational campaign of four months was performed, covering different seasons of the year, in which the seawater temperature was different enough. As the seawater temperature cannot be controlled, the influence of this parameter in the operation of the desalination module could only be assessed through its natural variability. These experiments were made during several hours per day, in the periods of maximum sunshine in all cases, and maintaining the operational conditions as controlled as possible. In order to evaluate the stability of the operation, in each test a setpoint value of hot feed temperature (T1) among $60,65,70,75$ and $80^{\circ} \mathrm{C}$, and a set point value of feed flow rate (F1) among 90, 120, 150, and $1801 \mathrm{~h}^{-1}$ were established.

The desalination device was started when the solar system reached a suitable temperature, depending on the hot feed temperature and flow rate conditions chosen for the operation. The thermal power supply from the solar field was regulated for maintaining the temperature inside the membrane module as close as possible to the set -point. When the MDS-40B is booted up, the vacuum pump starts to extract air from the module immediately, and creates the necessary pressure difference inside the module for absorbing feed seawater from the corresponding tanks. Before entering the module, a small dose of antiscalant was regularly injected discontinuously in the feed, which was subsequently filtered with a $20-\mu \mathrm{m}$ pore size cartridge for additional protection of the membranes. The antiscalant was used two months after the beginning of the experimental campaign, when severe scaling was observed in the module and the heat exchanger, for avoiding its negative effects. The seawater flow sucked by the vacuum enters into the condenser and acts as cooling. As the activity of the vacuum pump is not adjustable, the cooling flow rate is not fully controllable and depends on the vacuum pressure of the condenser as well as the aperture of V1 and V2. Working with a larger amount of fresh cooling seawater than actually used in the feed is required for all the vapour to be condensed properly, as in the case of MED plants. The feed flow rate that goes out of the condenser to the heat exchanger (and hence into the steam raiser) is then adjusted varying the position of the manual valves, while the rest of the preheated cooling seawater is discarded as brine. V1 was only used for

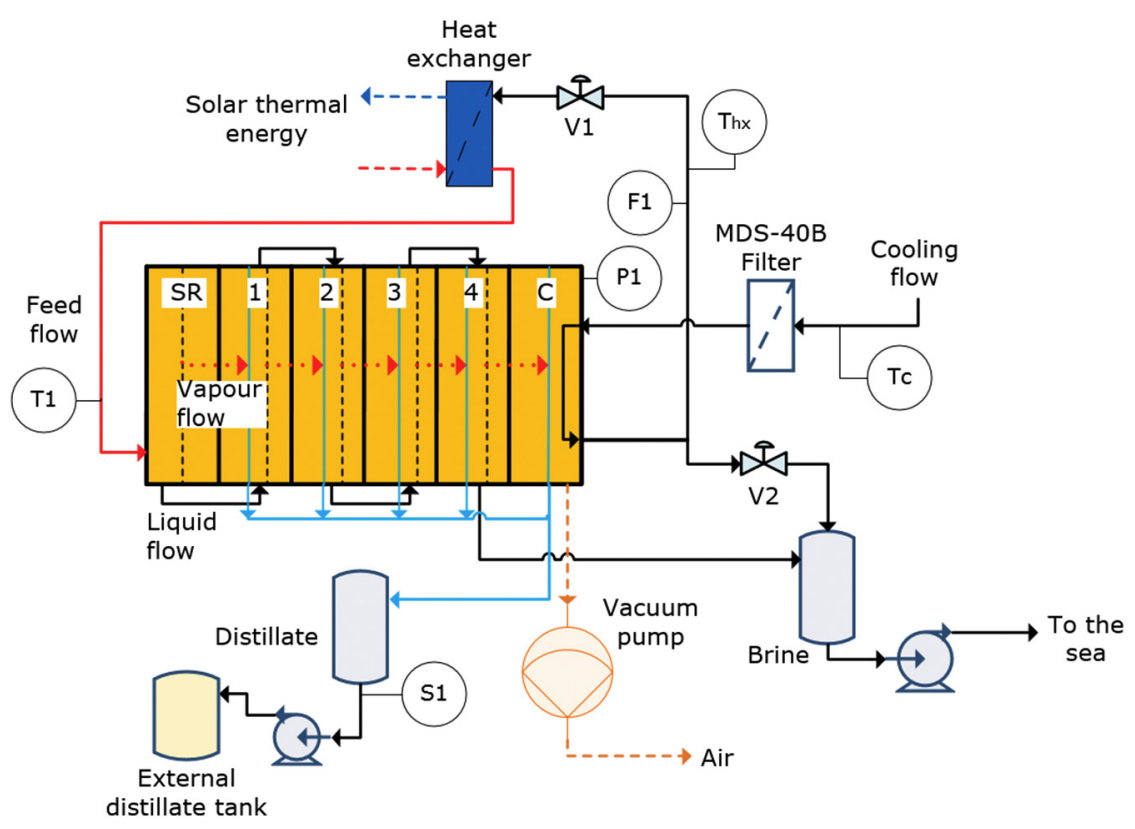

Fig. 3. Diagram showing the connectivity and the liquid and vapour flows in the MDS-40B. 
achieving the lowest values of hot feed temperature and feed flow rate (below $65{ }^{\circ} \mathrm{C}$ and $901 \mathrm{~h}^{-1}$ ), to prevent cooling flow rate to be higher than the discharge capacity of the brine pump, causing flooding of the module. In the rest of operating conditions, V1 stayed completely open, and feed flow rate was regulated by using only V2.

The solar heat is supplied from the solar field to the steam raiser through the heat exchanger. This heat and the reduced pressure inside the module, allow evaporating the feed partially in the heat exchanger at the vacuum-reduced boiling point. The biphasic flow enters into the steam raiser and is separated there. The vapour passes through the membrane pores and advances through the internal vapour channel to the first effect; the liquid continues to the first effect through the brine channel at the other side of the membrane. This way, the liquid phase is concentrated in solutes. The driving force for the effects is the temperature difference between the incoming and the produced vapour. The use of vacuum in the permeate side and of heat in the feed allows to increase this gradient. In each effect, the brine volumetric flow rate is reduced because it is concentrated further while it advances through the feed channel (space between consecutive PP foil and membrane). The new vapour produced from the brine passes through the membrane pores and is condensed on the PP foils of the next effect, delivering its latent heat through the PP foil to the circulating brine. Therefore, there is internal latent heat recovery by successive evaporations and condensations and the thermal energy brought into the system is recycled [36]. The vapour produced in the last effect is condensed inside the condenser, using the feed itself as cooling, as explained before. Therefore, there is additional heat recovery by preheating the feed with the latent heat of condensation of the vapour coming from the last effect. In a normal operation, after $20-30 \mathrm{~min}$, the vacuum pressure in the condenser drops until 100 mbar or even less, and steady state is reached. All the distillate produced in every effect is driven along internal channels to the distillate collection vessel, and from there it is pumped out discontinuously to an auxiliary tank. On the other hand, the brine is also stored temporarily in the corresponding vessel, and then rejected back to the sea.

In order to verify the chemical quality of the production, several samples of the distillate, the cooling (or feed) seawater and the brine were taken regularly for measuring their electrical conductivity and temperature (CM $35+$ with probe 5060, Crison - Hach Lange S.L.U., Spain). The feed flow rates of distillate and brine were also checked manually several times to verify the automatic sensors. At the end of each experiment, the thermal supply was cut off and then the system was stopped. To guarantee replicable conditions in each experiment, the module was rinsed after each experiment was stopped, using the distillate stored during the daily test as feed, thus delaying possible scaling and pore wetting. In a normal continuous operation, this procedure would not be needed.

An evaluation of how the desalination system operates in a wide range of conditions, including the influence of seasonal variations in the seawater temperature, is presented in the next section. The performance of the system is evaluated in terms of its productivity and heat energy efficiency. The former is assessed by the distillate flux, the latter by calculating the gained output ratio (GOR), which is the ratio between the required energy for evaporating the distillate production and the thermal energy supplied for producing this amount of distillate [44].

\section{Results and discussion}

\subsection{Distillate production}

For evaluating the performance of the MDS-40B desalination unit, an experimental campaign was performed with different operating conditions (namely, T1 and F1). Fig. 4 and Table 2 show the measured distillate flux in each case. It is expected that the distillate flux increases with the hot feed temperature and the feed flow rate because the vapour pressure gradient between both sides of the membrane pores becomes larger and thus the amount of vapour produced increases. This trend with the feed flow rate is different to that observed by Mohamed et al. [36] because in their study, the thermal power supplied to the steam raiser was maintained constant, and hence the hot feed temperature decreased as the feed flow rate increased. The maximum distillate fluxes for F1 up to $120 \mathrm{~h} \mathrm{~h}^{-1}\left(7.21 \mathrm{~h}^{-1} \mathrm{~m}^{-2}\right)$ were obtained working with the maximum $\mathrm{T} 1\left(80^{\circ} \mathrm{C}\right)$. However, when $\mathrm{F} 1=1501 \mathrm{~h}^{-1}$ was used, the highest production observed $\left(8.51 \mathrm{~h}^{-1} \mathrm{~m}^{-2}\right)$ was obtained at $\mathrm{T} 1=75^{\circ} \mathrm{C}$. Because of that, these latter operational conditions were established as the optimum and therefore considered as nominal in further comparisons. For $\mathrm{T} 1=80^{\circ} \mathrm{C}$ at F1 $=1501 \mathrm{~h}^{-1}$, and for every $\mathrm{T} 1$ when $\mathrm{F} 1$ was $180 \mathrm{lh}^{-1}$, a severe decrease of distillate flux was observed. Moreover, in some cases $\left(\mathrm{F} 1=1801 \mathrm{~h}^{-1}\right.$ and $\mathrm{T} 1=75$ and $80^{\circ} \mathrm{C}$ ), the unit could not even operate due to critical stops (not enough vacuum inside).

Recovery ratios calculated were also dependent on the hot feed temperature, but not on the feed flow rate used (Fig. 5 and Table 2). In the range of $\mathrm{T} 1$ tested, an increase of $5{ }^{\circ} \mathrm{C}$ in the steam raiser increased the recovery ratio by around $5 \%$. As expected, the highest values of recovery ratio were reached for the highest hot feed temperature: a value of around $40 \%$ at $80^{\circ} \mathrm{C}$. In the experiment in which the distillate flux was maximum $\left(8.51 \mathrm{~h}^{-1} \mathrm{~m}^{-2}\right)$, a recovery ratio of $36.1 \%$ was obtained. Working above the critical point given by $\mathrm{F} 1=1501 \mathrm{~h}^{-1}$ and $\mathrm{T} 1=75{ }^{\circ} \mathrm{C}$ affected strongly the values of recovery ratio. At $\mathrm{F} 1=1801 \mathrm{~h}^{-1}$, values less than half the ones operating at $1501 \mathrm{~h}^{-1}$ were achieved. Considering the experiment at $1501 \mathrm{~h}^{-1}$ and $80^{\circ} \mathrm{C}$, only $27.3 \%$ of the feed was recovered, less than operating even at $70^{\circ} \mathrm{C}$.

As indicated above, the only measurement available inside the module was the absolute pressure in the condenser. This is represented in Fig. 6 as a function of the hot feed temperature for different feed flow rates. For operation with $\mathrm{F} 1=1501 \mathrm{~h}^{-1}$, the absolute pressure in the condenser increased at $\mathrm{T} 1=80^{\circ} \mathrm{C}$ up to $230 \mathrm{mbar}, 70 \%$ more than at $75^{\circ} \mathrm{C}$. Similar anomalously high values of pressure were observed in the condenser when $\mathrm{F} 1$ value of $180 \mathrm{~h} \mathrm{~h}^{-1}$ was used. The cooling flow rate in the condenser can be calculated through a mass balance, since feed flow rate and brine discharge were measured. Fig. 7 represents the cooling flow rates at different hot feed temperatures and feed flow rates. In general, the higher the absolute pressure in the condenser, the lower the cooling flow rate was, because of less suction of the vacuum pump.

These results suggest that there was a limitation in the cooling capacity of the unit when working at high feed flow rate and temperature. The vapour reaching the condenser must be condensed using a seawater flow as cooling, which is sucked by the vacuum pump. Vapour production in the module increases with both operational parameters, and it can be too much for the condenser to cope with. The loss of distillate production beyond the critical point of operation indicates that the increase of vapour production with the operational conditions surpassed a certain limit above which its full condensation could not be achieved, thus the high pressure in the condenser. Because of that, there was a decrease of the suction of seawater, and therefore of the cooling flow rate, which reduced the condensation even more. In some cases, the system could reach a steady operation working at higher pressure in the condenser with reduced efficiency, thus the lower distillate flux. In the extreme cases, an equilibrium point could not be achieved, and the pressure in the condenser increased until the maximum limit set by the manufacturer ( 250 mbar) was reached. This resulted in a critical stop of the unit: the electronic control switched off the machine when the excessive absolute pressure was detected. As seen in Table 2, this was the case for the highest feed flow rate and temperatures. For operating at those conditions with a larger generation of vapour and thus a higher demand of cooling, more cooling flow rate would be needed. Although the different operation conditions complicate the comparison with previous studies using similar four-effect V-MEMD units, for the lowest feed flow rate $\left(901 \mathrm{~h}^{-1}\right)$ and hot temperature $70^{\circ} \mathrm{C}$ it is possible to 


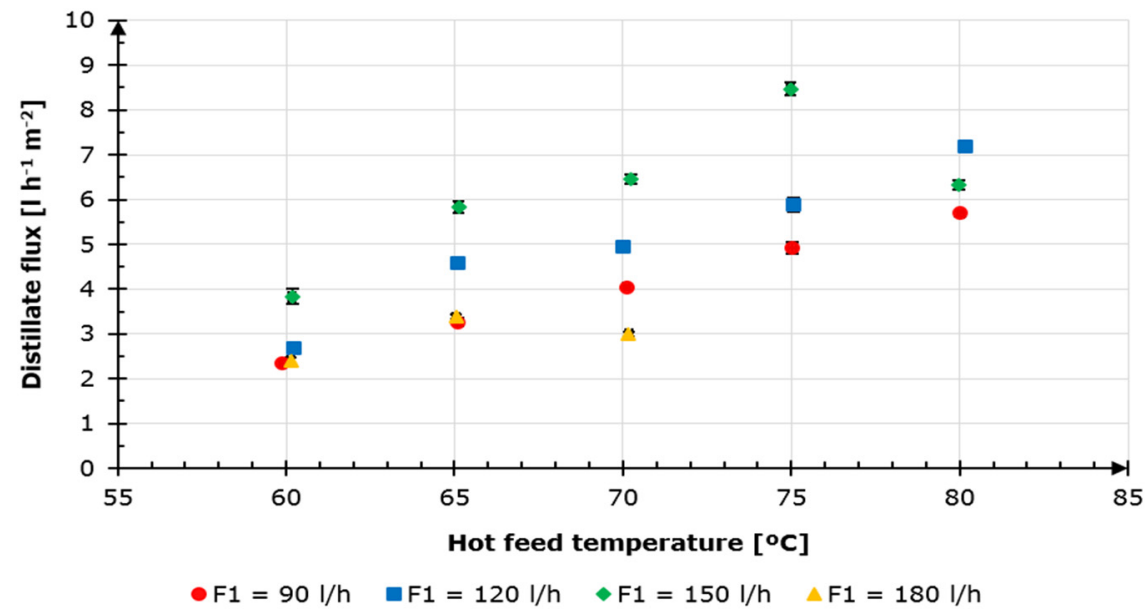

Fig. 4. Effect of hot feed temperature and feed flow rate in the distillate flux (error bars are present, but are smaller than dots in most cases).

Table 2

Operational conditions for the experiments shown in Figs. 4-7, and results obtained.

\begin{tabular}{lllll}
\hline $\begin{array}{l}\text { Measured F1 } \\
{\left[1 \mathrm{~h}^{-1}\right]}\end{array}$ & $\begin{array}{l}\text { Measured T1 } \\
{\left[{ }^{\circ} \mathrm{C}\right]}\end{array}$ & $\begin{array}{l}\text { Distillate flux } \\
{\left[1 \mathrm{~h}^{-1} \mathrm{~m}^{-2}\right]}\end{array}$ & $\begin{array}{l}\text { Recovery } \\
\text { ratio [\%] }\end{array}$ & GOR [-] \\
\hline 90.8 & 59.9 & 2.4 & 16.6 & 1.92 \\
90.2 & 65.1 & 3.3 & 23.2 & 2.33 \\
91.0 & 70.1 & 4.0 & 28.4 & 2.13 \\
90.5 & 75.0 & 4.9 & 34.8 & 2.29 \\
90.4 & 80.0 & 5.7 & 40.3 & 2.09 \\
120.2 & 60.2 & 2.7 & 14.2 & 1.82 \\
120.0 & 65.1 & 4.6 & 24.4 & 2.68 \\
120.1 & 70.0 & 5.0 & 26.4 & 2.69 \\
120.3 & 75.1 & 5.9 & 31.3 & 2.75 \\
120.3 & 80.2 & 7.2 & 38.3 & 2.69 \\
150.1 & 60.2 & 3.8 & 16.3 & 2.20 \\
150.3 & 65.1 & 5.8 & 24.8 & 2.67 \\
147.8 & 70.2 & 6.5 & 30.0 & 3.05 \\
150.1 & 75.0 & 8.5 & 36.1 & 3.19 \\
147.9 & 80.0 & 6.3 & 27.3 & 2.26 \\
179.8 & 60.1 & 2.4 & 8.5 & 1.77 \\
179.1 & 65.0 & 3.4 & 12.1 & 2.31 \\
180.6 & 70.2 & 3.0 & 11.2 & 2.14 \\
180.0 & 75.0 & $*$ & $*$ & $*$ \\
180.0 & 80.0 & $*$ & $*$ & $*$ \\
& & & &
\end{tabular}

(*) Not performed due to critical stop of the unit.

compare with the results of Minier-Matar et al. using seawater [34] and groundwater with saline concentration similar to seawater [40].
Distillate fluxes reported were larger than in the MDS-40B unit: $4.81 \mathrm{~h}^{-1} \mathrm{~m}^{-2}$ and $51 \mathrm{~h}^{-1} \mathrm{~m}^{-2}$ respectively, but their system had larger cooling flow rate $\left(810 \mathrm{~h} \mathrm{~h}^{-1}\right)$ at $20^{\circ} \mathrm{C}$ cooling temperature.

The cooling capacity of the unit can also be affected by the available seawater temperature. During the tests shown above, the average seawater temperature was $20^{\circ} \mathrm{C}$. A cooler seawater temperature could supply more cooling power with the same operational conditions. As a matter of fact, the nominal conditions of a similar unit reported by Aquaver in the North Sea were $\mathrm{F} 1=1501 \mathrm{~h}^{-1}$ and $\mathrm{T} 1=80^{\circ} \mathrm{C}$, while in The Maldives the productivity was maximum at a $\mathrm{T} 1$ of $65^{\circ} \mathrm{C}$ [45]. As discussed above, in the study shown here in the Mediterranean Sea the optimal (nominal) conditions were $\mathrm{F} 1=150 \mathrm{l} \mathrm{h}^{-1}$ and $\mathrm{T} 1=75^{\circ} \mathrm{C}$. To investigate the effect of the cooling temperature, couples of experiments were performed with the same operational conditions but for extreme values of the seawater temperature far from the average. Fig. 8 shows the distillate flux for $\mathrm{F} 1=150 \mathrm{~h} \mathrm{~h}^{-1}$ and different values of $\mathrm{T} 1$ at different times of the year when seawater temperatures were significantly different. Distillate productions were higher in case A (average seawater temperature of $(16 \pm 2)^{\circ} \mathrm{C}$ ) than in case B (average seawater temperature of $\left.(24 \pm 2){ }^{\circ} \mathrm{C}\right)$, because of better vapour condensation and thus lower absolute pressure inside the condenser. An increase of about $8{ }^{\circ} \mathrm{C}$ in the cooling temperature resulted in production losses up to $44 \%$. As discussed before, for this feed flow rate there was no advantage in increasing the hot feed temperature up to $80^{\circ} \mathrm{C}$, neither in one period nor in the other: the distillate production was similar to that achieved when it was operated at $70{ }^{\circ} \mathrm{C}$ in both periods of the year.

In conclusion, the main drawback observed in the unit was that

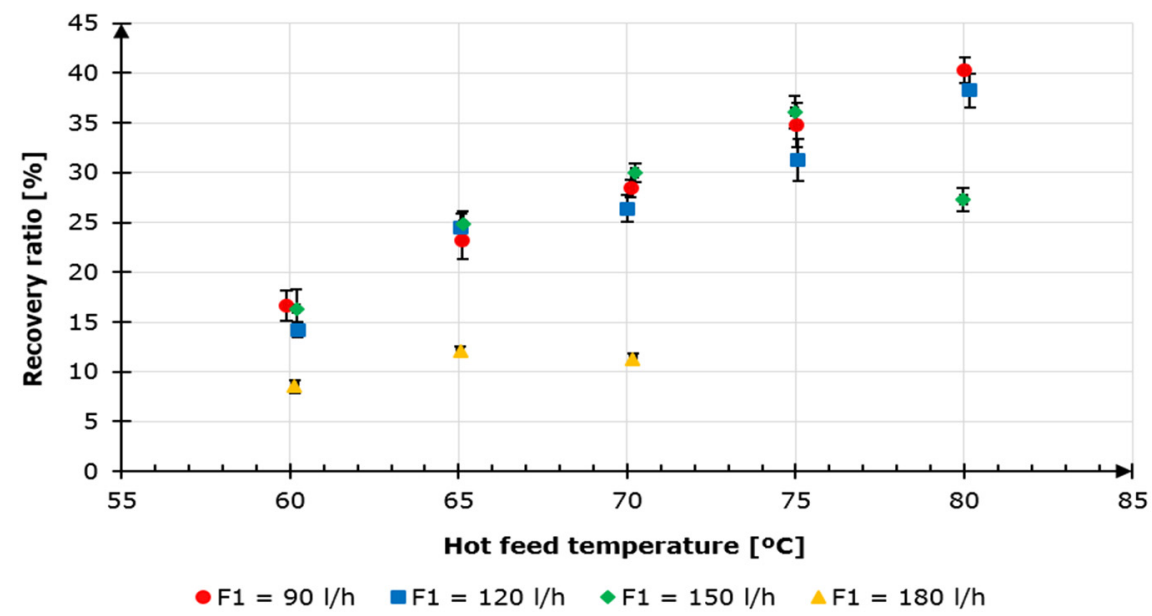

Fig. 5. Effect of hot feed temperature and feed flow rate in the recovery ratio (error bars are present, but are smaller than dots in some cases). 


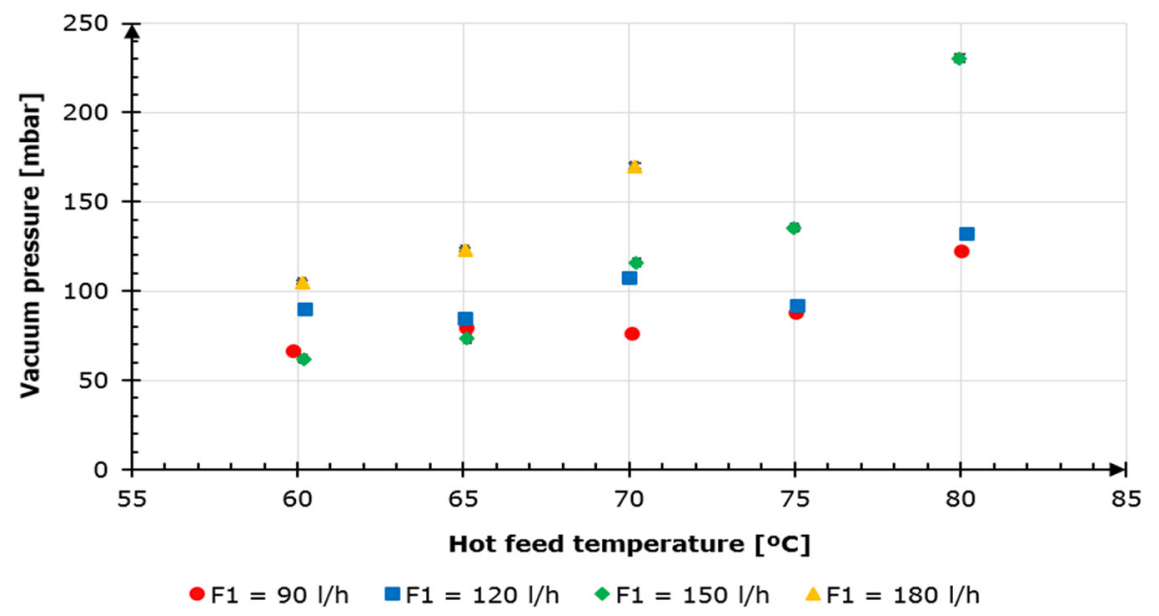

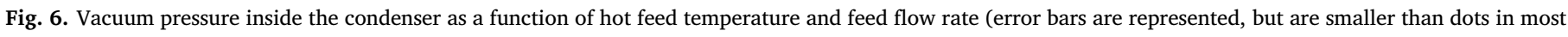
cases).

there is a limiting operation point related to the restricted cooling capacity of the system. On one hand, seawater temperature is a constraint. On the other hand, if a higher cooling flow rate could be achieved (perhaps using a circulation pump independent from the vacuum pump), or heat exchange could be improved in the condenser (using a larger one or improving the heat transfer rate), the operation could be extended to conditions with a larger generation of vapour meeting the subsequently higher demand of cooling.

\subsection{Energy efficiency}

The multi-effect design allows reusing energy as latent heat in the consecutive effects, and the latent heat of condensation in the condenser is recovered as sensible heat by preheating the feed through the condenser. Both actions increase the heat efficiency, producing more distillate with less thermal energy consumption in the MDS-40B unit. Fig. 9 shows the values of the GOR obtained for each experiment as a function of hot feed temperature (T1) and feed flow rate (F1). GOR increased with $\mathrm{F} 1$ and $\mathrm{T} 1$, up to $1501 \mathrm{~h}^{-1}$ and $75^{\circ} \mathrm{C}$, respectively. However, the effect of $\mathrm{F} 1$ was higher for values of $\mathrm{T} 1$ larger than $65^{\circ} \mathrm{C}$, due to the increment in the amount of vapour produced in the module when more feed water was introduced, which improves the internal latent heat recovery. The maximum GOR obtained in this system was 3.19 , for $\mathrm{T} 1=75{ }^{\circ} \mathrm{C}$ and $\mathrm{F} 1=1501 \mathrm{~h}^{-1}$, the same conditions that produced the highest distillate flux $\left(8.51 \mathrm{~h}^{-1} \mathrm{~m}^{-2}\right)$.

With the condenser and the cooling power available in the MDS-40B system, a severe loss of thermal efficiency was observed when working at feed flow rate of $1501 \mathrm{~h}^{-1}$ and hot feed temperature higher than $75^{\circ} \mathrm{C}$, or at feed flow rate of $1801 \mathrm{~h}^{-1}$ independently on the hot feed temperature (yellow bars in Fig. 9). As the vapour generation increases, so does the demand of cooling flow in the condenser, but the cooling flow rate depends on the suction from the vacuum pump, thus the larger demand of cooling flow is thwarted by the higher pressure in the condenser. This results in an overheating of the condenser for those operating conditions (Fig. 10). This overheating is the result of a feedback effect and illustrates the performance limitation of the system: the accumulation of vapour in the condenser means that not enough liquid feed reaches the steam raiser, so there is not enough liquid to condensate the steam in the effects, and this increases even more the amount of steam that reaches the condenser.

The heat efficiency obtained with the MDS-40B unit improved that obtained with similar modules using separate cooling circuits in the condenser. For feed flow rate $1201 \mathrm{~h}^{-1}$, GOR was 2.7 times larger than that reported by Mohamed et al. [39], despite using higher feed salinity in the present work. The maximum GOR of 3.19 corresponds to a specific thermal energy consumption of $207.7 \mathrm{kWh}_{\mathrm{th}} \mathrm{m}^{-3}$, similar to that given by Minier-Matar et al. [40] for a V-MEMD unit with the same number of effects, using groundwater with similar salinity to seawater and larger cooling flow rate, as discussed above. GOR values reported by Zhao et al. [32] were higher, but the energy analysis in that work was done using tap water of very low salinity. The values of GOR in this work are slightly smaller $(16 \%)$ than the maximum reported by Ong

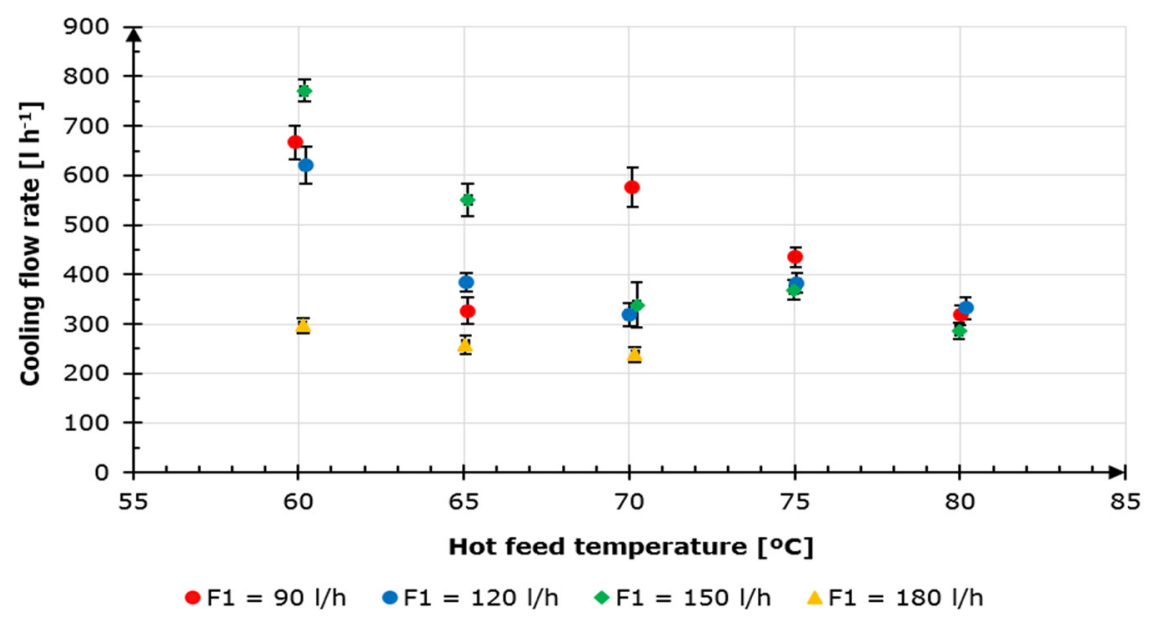

Fig. 7. Available cooling flow rate as a function of hot feed temperature and feed flow rate. 


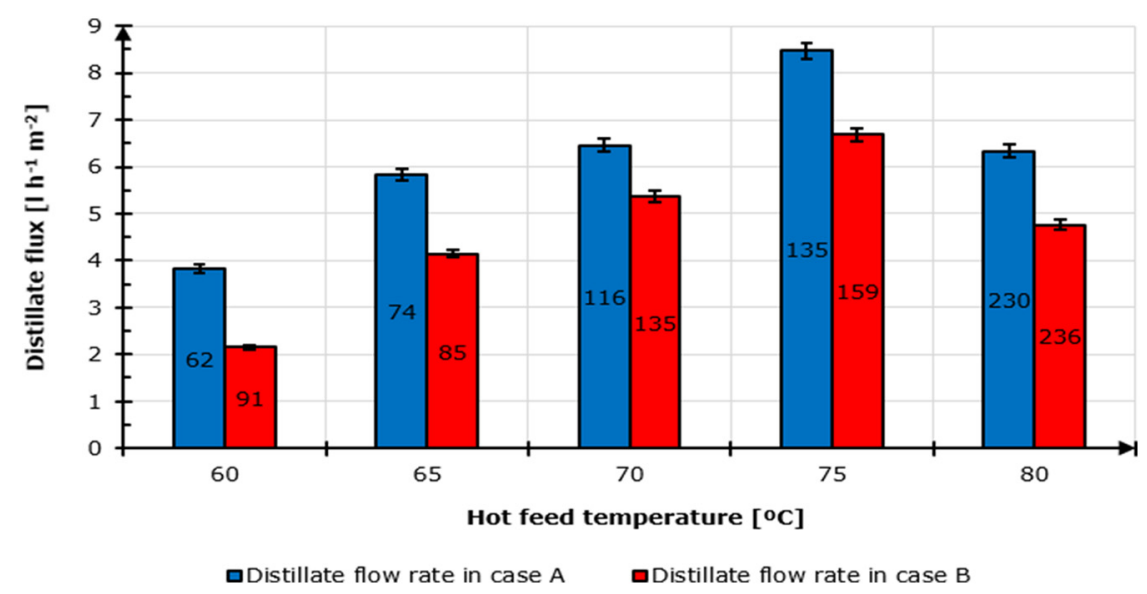

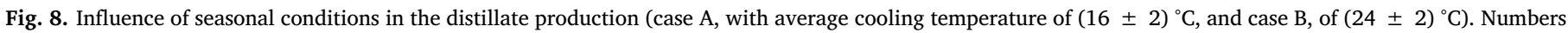
inside bars indicate the vacuum pressure in each experiment.

et al. [41] for a six-effect V-MEMD module with seawater as feed using also a separate cooling circuit in the condenser. However, the difference in operating conditions between the different studies hinders a proper comparison. A better comparison can be made with a previous V-MEMD prototype made also by Aquaver BV and called WTS-40A (Fig. 11). The latter had two distillation effects more than the former, membrane area $5.76 \mathrm{~m}^{2}$, and worked with lower feed flow rates. More importantly, it used a separate cooling circuit with no latent heat recovery from the condenser. The values of GOR obtained for the WTS-40A are also indicated in Fig. 9 (grey bars). These are not the highest values obtained for the WTS-40A unit [42], but are the ones for experiments comparable with those of the MDS-40B (similar hot feed and condenser temperatures). The design and size of the constituent frames in the effects of the WTS-40A module are the same as in those forming the MDS-40B module, so the velocity of both liquid and vapour through the internal channels are the same in both modules when working at similar feed flow rates. Feed flow rate in the WTS-40A was determined by the vacuum level in the operation and could not be controlled, however. Considering that the operational feed flow rate corresponding to the experiments shown in Fig. $9\left(60 \mathrm{lh}^{-1}\right)$ was lower than the minimum in the MDS-40B $\left(90 \mathrm{l} \mathrm{h}^{-1}\right)$, and the GOR values seem to match the trend of the latter, there does not seem to be a noticeable increase due to the additional two effects. The recovery ratios, however, were larger in the WTS-40A (up to 56\%) because of the bigger number of effects [46].

The fact that the heat efficiency of the MDS-40B was larger than in other four-effect V-MEMD modules and comparable with that of the WTS-40A with two effect more shows the benefits of recovering the latent heat in the condenser as sensible heat for preheating the feed. In addition, in the WTS-40A unit there was a larger influence of the ambient temperature in the cooling circuit, as opposed to the MDS-40B unit, which uses direct seawater as cooling. This less steady operation is reflected in the bigger dispersion of the data (larger error bars in Fig. 9). The WTS-40A prototype had too many operational problems to allow for a characterization as complete as in the MDS-40B, but a limitation in the condenser capacity was also observed when operating at hot feed temperatures and feed flow rates larger than $60 \mathrm{lh}^{-1}$ with the available cooling temperatures (in that case a separate circuit was used, using water in a closed circuit refrigerated with an air cooler, so ambient temperature was the main constraint).

The main energy used by the unit is thermal energy. However, as discussed in Section 2, there is also a consumption of electricity. The typical measured values for the specific electrical energy consumption were between 5 and $20 \mathrm{kWh}_{\mathrm{el}} \mathrm{m}^{-3}$. This is much larger than in other MD systems, and is mostly due to the vacuum pump. The efficiency of small pumps is lower than that of large pumps, so increasing the size of the unit could decrease this value. It is worth considering, however, that an increase in size would not necessarily decrease the specific thermal energy consumption, since the upscaling of memsys modules is generally done by adding more frames to the effects. Of course, if the upscaling involved also the addition of effects, then the thermal efficiency would increase, as discussed above.

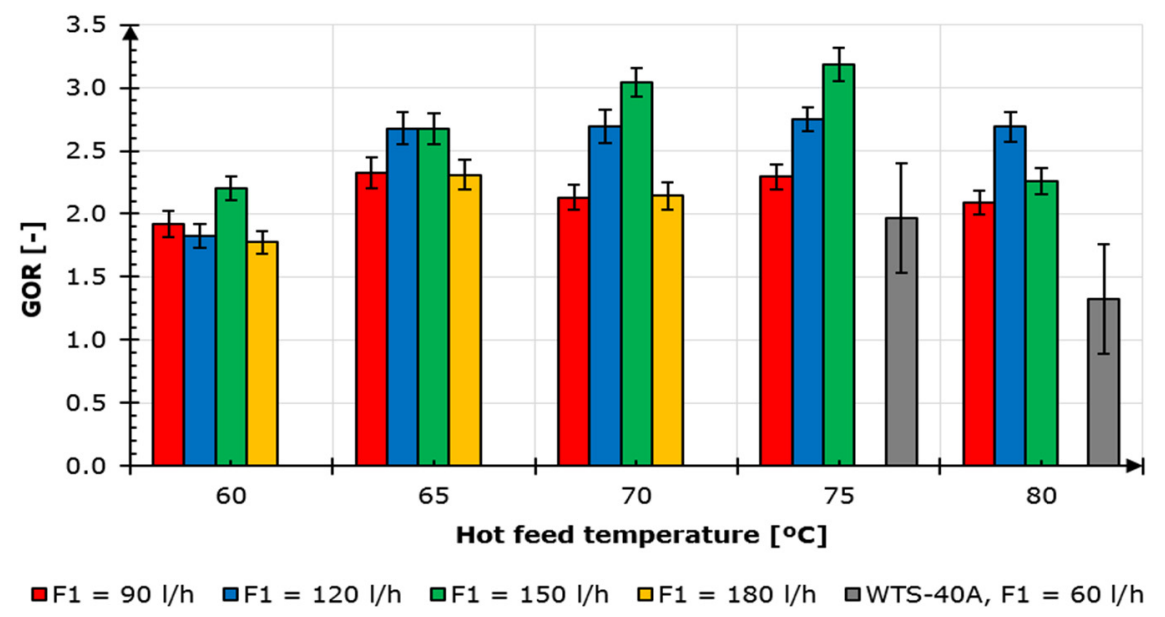

Fig. 9. Gained output ratio as a function of hot feed temperature and feed flow rate into the module. 


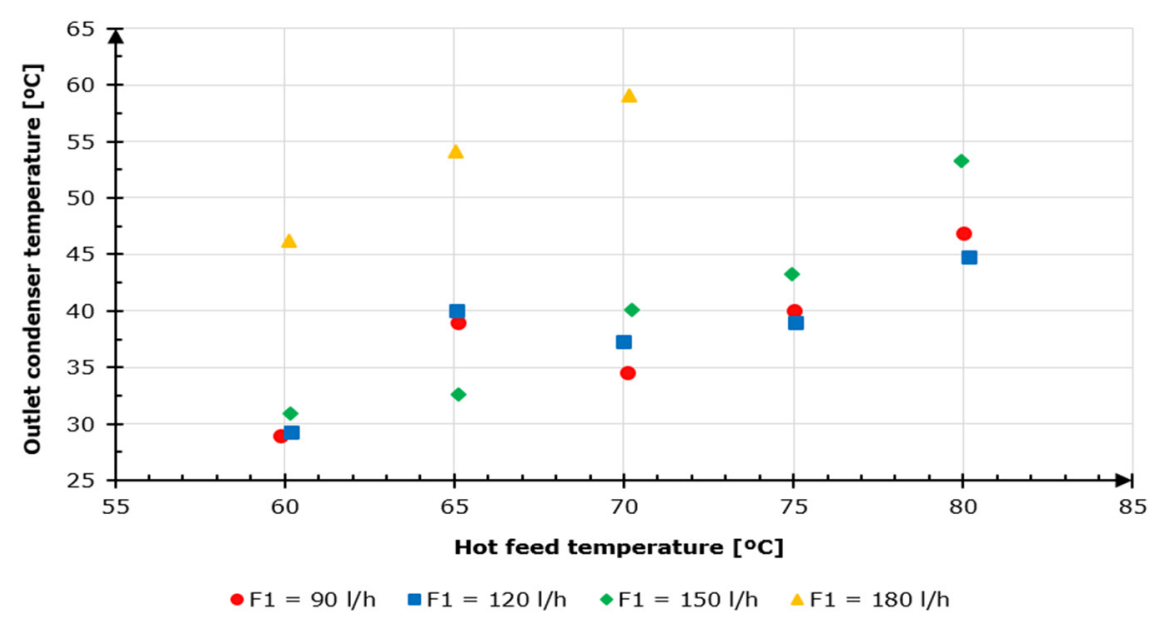

Fig. 10. Temperature of the cooling flow exiting the condenser and entering the heat exchanger of the MDS-40B unit for different operation conditions (error bars are present, but are smaller than dots in all cases).

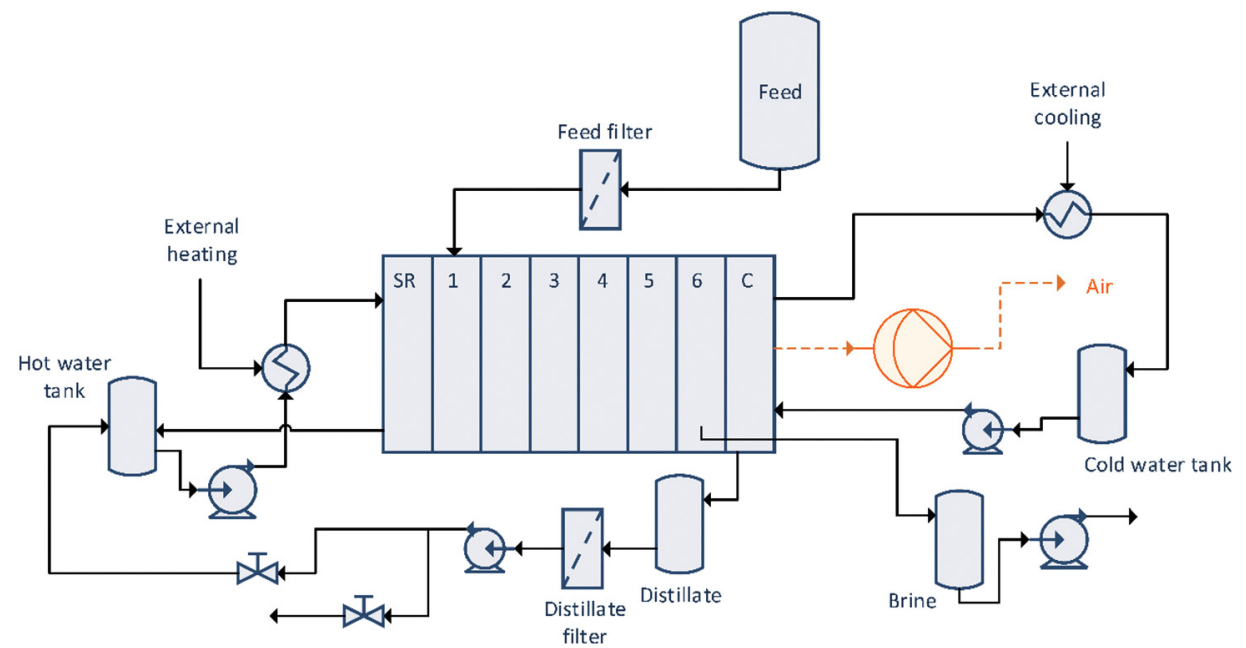

Fig. 11. Schematic diagram of the WTS-40A unit.

\subsection{Distillate quality}

The quality of the distillate was analysed by measuring the electrical conductivity of the distillate. The MDS-40B makes the distillate discharges discontinuously, as explained in Section 2.2. Fig. 12 illustrates its typical behaviour during twelve consecutive discharges. The quality was worse in the first discharge, but usually by the fourth discharge the electrical conductivity was already lower than $5 \mu \mathrm{S} \mathrm{cm}{ }^{-1}$, maintaining this level from then on. The total mass of distillate after about $1 \mathrm{~h}$ of operation had less than $10 \mu \mathrm{S} \mathrm{cm} \mathrm{cm}^{-1}$ conductivity, reaching a global salt rejection factor of $99.98 \%$, comparable to that obtained in previous studies [34]. The higher salinity of the distillate at the beginning of the experiment is a usual phenomenon observed in the operation of commercial membrane distillation [47]. There are two possible reasons for

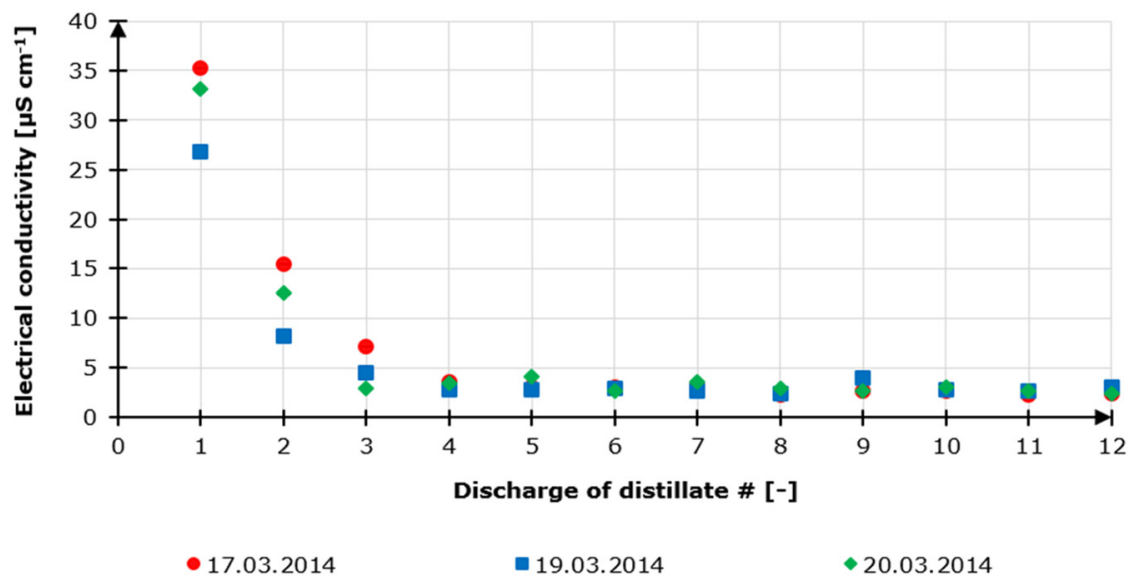

Fig. 12. Evolution of distillate conductivity during several discharges in three different experiments (error bars are present, but are smaller than dots in all cases). 


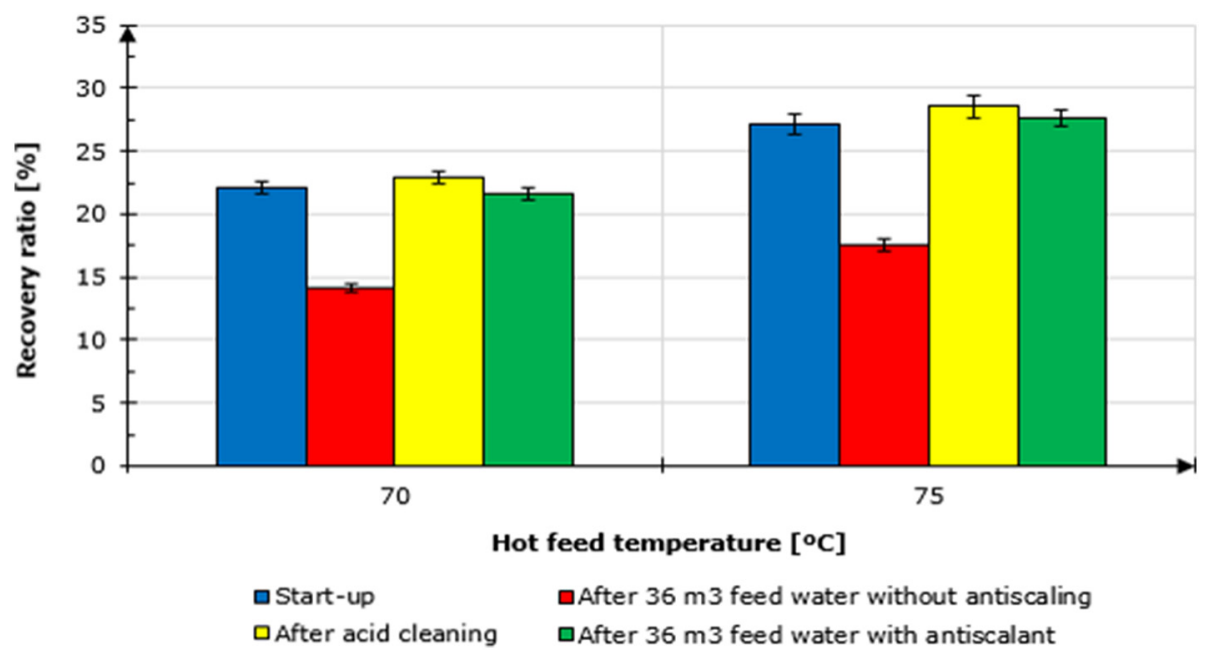

Fig. 13. Effect of acid membrane cleaning in the distillate production.

this. On one hand, when the system is stopped salt crystals can be formed inside the membrane pores, and are subsequently washed out by the first production of distillate [48]. On the other hand, since the pore size of the membrane is in fact a distribution around the mean value of $0.2 \mu \mathrm{m}$, there can be a minority of pores large enough to be non-hydrophobic. When the system is stopped, this small leakage can accumulate in the distillate channel, to be released in the first distillate discharge. To prevent this, in the MDS-40B when the vacuum pump is off, the distillate channel leaks to a chamber placed at the bottom of the effects, connected by a tube to the brine tank. The first discharge of the brine removes these little residuals. The effectiveness of this system is reflected in the fact that the high conductivity value of the first distillate was considerably much lower (never above $50 \mu \mathrm{sm}^{-1}$ ) than observed in the operation of other MD systems at pilot-scale [30].

\subsection{Membrane scaling and cleaning}

Since operation was performed with real seawater, the effect of scaling was analysed by comparing experiments done along the time under the same conditions of feed flow rate $\left(150 \mathrm{lh}^{-1}\right)$ and hot feed temperature (choosing two cases at 70 and $75^{\circ} \mathrm{C}$ ). The coloured bars in Fig. 13 represent the recovery ratio obtained in each experiment. The measurements correspond to single days and not average of different experiments performed under the same conditions. Thus, cooling temperature was affected by the natural variability of the seawater temperature. Tests were selected with cooling temperatures as similar as possible (inside a range of $\pm 2{ }^{\circ} \mathrm{C}$ ), in order to minimize its influence.

Blue bars correspond to the initial state of the MDS-40B unit, so they can be considered as the reference state. After processing around $36 \mathrm{~m}^{3}$ of feed seawater inside the module, severe decline of distillate production (up to $36 \%$ ) was observed at both hot feed temperatures. This excessive loss of performance could not be explained by variations in the cooling temperature (little, as explained), but by the scaling due to the use of natural seawater. The module could not be disassembled to examine the membranes, but an inspection of the heat exchanger showed that a thick mineral layer was formed on its plates (Fig. 14), and salt slurry was found in the pipes (Fig. 15). A chemical analysis showed that it is mainly composed by calcium ( $28 \mathrm{wt} \%$ ), with traces of other cations like sodium, magnesium and potassium. This suggested that the membranes might be affected too, as has already been observed in other pilot-scale experiments [47]. The scaling slabs were manually removed and cleaned from the heat exchanger, which was then reassembled in the desalination unit. In order to clean the membrane module, a solution of $2 \mathrm{gl}^{-1}$ of citric acid was used as feed during $1 \mathrm{~h}$, recirculating it constantly without adding heat. After the cleaning, the

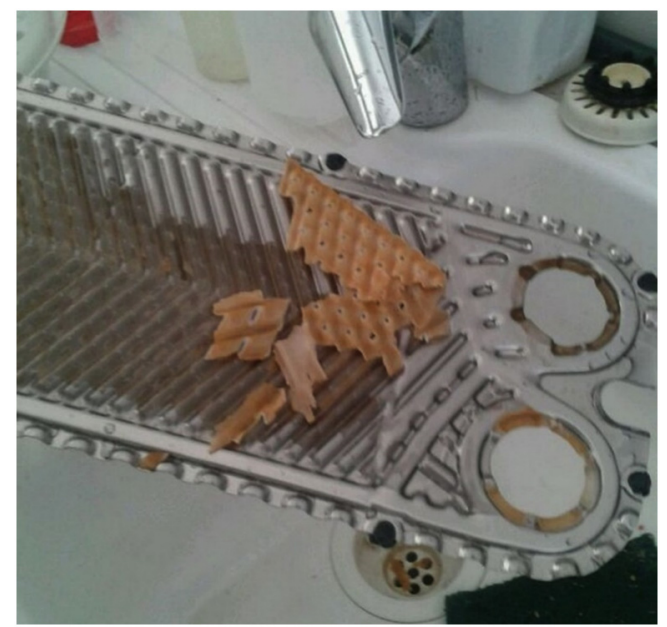

Fig. 14. Slabs of scaling over a plate of the heat exchanger of the desalination unit.

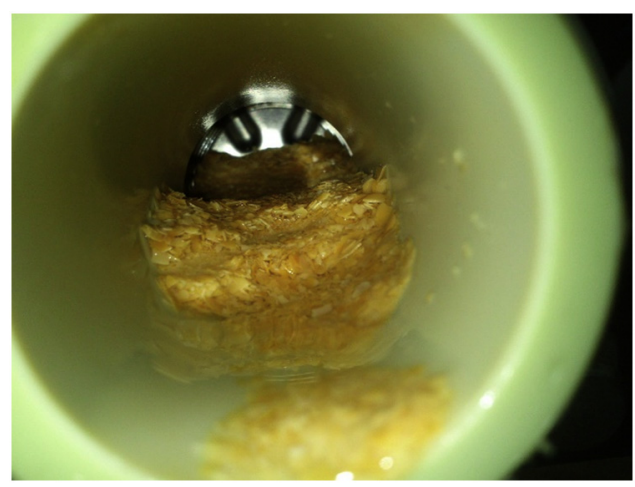

Fig. 15. Feed seawater inlet of the heat exchanger after processing $36 \mathrm{~m}^{3}$ of seawater without the use of antiscalant.

performance of the unit was practically restored, as shown by the yellow bars being very similar to the blue bars in Fig. 13.

The last measure considered was the addition of a biodegradable antiscalant for avoiding or delaying the formation of hard scaling, and improving the operation. A dose of $5 \mathrm{ml} \mathrm{m}^{-3}$ in feed seawater was used thereinafter with excellent results in a comparable time of operation. No scaling was detected inside the heat exchanger or in the piping after a campaign with equivalent duration to the previous one in which 
scaling was formed (processing again around $36 \mathrm{~m}^{3}$ of feed seawater) and, as shown by the green bars in Fig. 13, no big losses of distillate production were observed.

\section{Conclusions}

In this paper, an innovative desalination system based on V-MEMD was evaluated for desalination of Mediterranean seawater. The performance of the MDS-40B unit built by Aquaver using a memsys module was analysed in terms of distillate productivity and heat efficiency for different operational conditions. The optimal performance was obtained operating at feed flow rate $1501 \mathrm{~h}^{-1}$ and hot feed temperature $75{ }^{\circ} \mathrm{C}$. The maximum distillate flux at these conditions was $8.51 \mathrm{~h}^{-1} \mathrm{~m}^{-2}$, with recovery ratio of $36 \%$, GOR of 3.19 , and specific thermal energy consumption around $200 \mathrm{kWh}_{\mathrm{th}} \mathrm{m}^{-3}$.

The innovative aspects of the MDS-40B unit were assessed. The heat-saving strategy of using seawater directly as cooling in the condenser, preheating it by means of the latent heat of condensation of the vapour coming from the last effect, and taking a fraction of this preheated seawater as feed for the module, was demonstrated by a resulting GOR comparable to that of a similar unit with two effects more. A limitation was identified that hinders a proper performance of the system in a wider range of operational conditions that could potentially increase the productivity. This is the limited cooling capacity of the system, which is constrained by the seawater temperature and the restricted capability of the vacuum pump to create a large cooling flow in the condenser.

Distillate quality in the experiments was lower than $50 \mu \mathrm{cm}^{-1}$ from the beginning of the operation, and reached smaller conductivities (less than $5 \mu \mathrm{S} \mathrm{cm}^{-1}$ ) in less operational time than other desalination systems previously studied. This proved the effectiveness of the mechanism for leak removal in the distillate channel when the unit is not operated.

Finally, it was found that preventive measurements are necessary against scaling formation when working with seawater. When scaling was formed after several months of operation, washing the desalination unit with citric acid in concentration $2 \mathrm{gl}^{-1}$ restored the performance of the unit. Thereinafter, the use of a biodegradable antiscalant prevented the formation of scaling during a similar time of operation.

Ultimately, V-MEMD was demonstrated as a feasible technology for seawater desalination, which performs better the cooler the seawater is, and should find a niche in applications where high salinity makes other technologies more complicated. In further works, the combination with solar energy should be studied to assess the effects of the solar energy variations and the influence of the operation of the solar collectors on the total energy consumption of the solar desalination process.

\section{Acknowledgements}

The authors wish to thank the financial support given by the European Commission under the Switch-Asia project Zero Carbon Resorts (reference: DCI-ASIE/2013/334140).

\section{References}

[1] M. Khayet, T. Matsuura (Eds.), Membrane Distillation - Principles and Applications, Elsevier, 2011.

[2] A. Alkhudhiri, N. Darwish, N. Hilal, Membrane distillation: a comprehensive review, Desalination 287 (2012) 2-18.

[3] E. Drioli, A. Ali, F. Macedonio, Membrane distillation: recent developments and perspectives, Desalination 356 (2015) 56-84.

[4] P. Wang, T.S. Chung, Recent advances in membrane distillation processes: membrane development, configuration design and application exploring, J. Membr. Sci. 474 (2015) 39-56.

[5] E. Drioli, A. Ali, F. Macedonio, Membrane operations for process intensification in desalination, Appl. Sci. 7 (2017) 100.

[6] D. González, J. Amigo, F. Suárez, Membrane distillation: perspectives for sustain able and improved desalination, Renew. Sust. Energ. Rev. 80 (2017) 238-259.

[7] N. Thomas, M.O. Mavukkandy, S. Loutatidou, H.A. Arafat, Membrane distillation research \& implementation: lessons from the past five decades, Sep. Purif. Technol. 189 (2017) 108-127.

[8] M. Khayet, Solar desalination by membrane distillation: dispersion in energy consumption analysis and water production costs (a review), Desalination 308 (2013) 89-101.

[9] Y. Zhang, Y. Peng, S. Ji, Z. Li, P. Chen, Review of thermal efficiency and heat recycling in membrane distillation processes, Desalination 367 (2015) 223-239.

[10] E. Guillén-Burrieza, J. Blanco, G. Zaragoza, D.C. Alarcón-Padilla, P. Palenzuela, M. Ibarra, et al., Experimental analysis of an air gap membrane distillation solar desalination pilot system, J. Membr. Sci. 379 (2011) 386-396.

[11] E. Guillén-Burrieza, G. Zaragoza, S. Miralles-Cuevas, J. Blanco, Experimental evaluation of two pilot-scale membrane distillation modules used for solar desalination, J. Membr. Sci. 409 (2012) 264-275.

[12] D. Woldemariam, A. Kullab, U. Fortkamp, J. Magner, H. Royen, A. Martin, Membrane distillation pilot plant trials with pharmaceutical residues and energy demand analysis, Chem. Eng. J. 306 (2016) 471-483.

[13] C.M. Guijt, I.G. Racz, J.W. Van Heuven, T. Reith, A.B. de Haan, Modelling of a transmembrane evaporation module for desalination of seawater, Desalination 126 (1999) 119-125.

[14] Q. He, P. Li, H. Geng, G. Zhang, J. Wang, H. Chang, Modeling and optimization of air gap membrane distillation system for desalination, Desalination 354 (2014) 68-75.

[15] H. Geng, Q. He, H. Wu, P. Li, C. Zhang, H. Chang, Experimental study of hollow fiber AGMD modules with energy recovery for high saline water desalination, Desalination 334 (2014) 55-63.

[16] D. Winter, J. Koschikowski, M. Wieghaus, Desalination using membrane distillation: experimental studies on full scale spiral wound modules, J. Membr. Sci. 375 (2011) 104-112.

[17] A. Hagedorn, G. Fieg, D. Winter, J. Koschikowski, T. Mann, Methodical design and operation of membrane distillation plants for desalination, Chem. Eng. Res. Des. 125 (2017) 265-281.

[18] H.C. Duong, P. Cooper, B. Nelemans, T.Y. Cath, L.D. Nghiem, Evaluating energy consumption of air gap membrane distillation for seawater desalination at pilo scale level, Sep. Purif. Technol. 166 (2016) 55-62.

[19] A. Ruiz-Aguirre, J.A. Andrés-Mañas, J.M. Fernández-Sevilla, G. Zaragoza, Comparative characterization of three commercial spiral-wound membrane distillation modules, Desalin. Water Treat. 61 (2017) 152-159.

[20] F. Banat, N. Jwaied, M. Rommel, J. Koschikowski, M. Wieghaus, Performance evaluation of the "large SMADES" autonomous desalination solar-driven membrane distillation plant in Aqaba, Jordan, Desalination 217 (2007).

[21] R. Schwantes, A. Cipollina, F. Gross, J. Koschikowski, D. Pfeifle, M. Rolletschek, V. Subiela, Membrane distillation: solar and waste heat driven demonstration plants for desalination, Desalination 323 (2013) 93-106.

[22] D. Winter, J. Koschikowski, S. Ripperger, Desalination using membrane distillation: flux enhancement by feed water deaeration on spiral-wound modules, J. Membr. Sci. 423-424 (2012) 215-224.

[23] J.I. Mengual, M. Khayet, M.P. Godino, Heat and mass transfer in vacuum membrane distillation, Int. J. Heat Mass Transf. 47 (4) (2004) 865-875.

[24] M.S. El-Bourawi, Z. Ding, R. Ma, M. Khayet, A frame work for better understanding membrane distillation separation process, J. Membr. Sci. 285 (1-2) (2006) 4-29.

[25] E.K. Summers, H.A. Arafat, J.H.V. Lienhard, Energy efficiency comparison of singlestage membrane distillation (MD) desalination cycles in different configurations, Desalination 290 (2012) 54-66.

[26] Y.-D. Kim, K. Thu, S.-H. Choi, Solar-assisted multi-stage vacuum membrane distillation system with heat recovery unit, Desalination 367 (2015) 161-171.

[27] H.W. Chung, J. Swaminathan, D.M. Warsinger, J.H.V. Lienhard, Multistage vacuum membrane distillation (MSVMD) systems for high salinity applications, J. Membr. Sci. 497 (2016) 128-141.

[28] Y. Zhang, Y. Peng, S. Ji, J. Qi, S. Wang, Numerical modeling and economic evaluation of two multi-effect vacuum membrane distillation (ME-VMD) processes, Desalination 419 (2017) 39-48.

[29] Y.L. Xing, C.-H. Qi, H.-J. Feng, Q.-C. Lv, G.-R. Xu, H.-Q. Lv, X. Wang, Performance study of a pilot-scale multi-effect vacuum membrane distillation desalination plant, Desalination 403 (2017) 199-207.

[30] A. Ruiz-Aguirre, J.A. Andrés-Mañas, J.M. Fernández-Sevilla, G. Zaragoza, Modeling and optimization of a commercial permeate gap spiral wound membrane distillation module for seawater desalination, Desalination 419 (2017) 160-168.

[31] W. Heinzl, S. Büttner, G. Lange, Industrialized modules for MED desalination with polymer surfaces, Desalin. Water Treat. 42 (2012) 177-180.

[32] K. Zhao, W. Heinzl, M. Wenzel, S. Büttner, F. Bollen, G. Lange, et al., Experimental study of the memsys vacuum multi-effect membrane distillation (V-MEMD) module, Desalin. Water Treat. 323 (2013).

[33] A. Chafidz, S. Al-Zahrani, M.N. Al-Otaibi, C.F. Hoong, T.F. Lai, M. Prabu, Portable and integrated solar-driven desalination system using membrane distillation for arid remote areas in Saudi Arabia, Desalination 345 (2014).

[34] J. Minier-Matar, A. Hussain, A. Janson, F. Benyahia, S. Adham, Field evaluation of membrane distillation technologies for desalination of highly saline brines, Desalination 351 (2014) 101-108.

[35] G. Naidu, Y. Choi, S. Jeong, T.M. Hwang, S. Vigneswaran, Experiments and modeling of a vacuum membrane distillation for high saline water, J. Ind. Eng. Chem. 20 (2014) 2174-2183.

[36] M. Wenzel, S. Büttner, W. Heinzl, S. Heinzl, Distillation of high concentrated salt solution by vacuum multi effect membrane distillation (VMEMD) of memsys, Water Pract. Technol. 10 (2015) 478-485.

[37] F. Kiefer, F. Schummer, A. Präbst, M. Spinnler, T. Sattelmayer, Theoretical and experimental study of multi-effect vacuum membrane distillation systems for liquid 
desiccant air conditioning and zero liquid discharge, Desalin. Water Treat. 69 (2017) 190-201.

[38] F.H. Choo, M.Kum Ja, K. Zhao, A. Chakraborty, E.T.M. Dass, M. Prabu, B. Li, S. Dubey, Experimental study on the performance of membrane based multieffect dehumidifier regenerator powered by solar energy, Energy Procedia 48 (2014) 535-542.

[39] E.S. Mohamed, P. Boutikos, E. Mathioulakis, V. Belessiotis, Experimental evaluation of the performance and energy efficiency of a vacuum multi-effect membrane distillation system, Desalination 408 (2017) 70-80.

[40] J. Minier-Matar, R. Sharma, A. Hussain, A. Janson, S. Adham, Field evaluation of membrane distillation followed by humidification/dehumidification crystallizer for inland desalination of saline groundwater, Desalination 398 (2016) 12-21.

[41] C.L. Ong, W. Escher, S. Paredes, A.S.G. Khalil, B. Michel, A novel concept of energy reuse from high concentration photovoltaic thermal (HCPVT) system for desalination, Desalination 295 (2012) 70-81.

[42] G. Zaragoza, A. Ruiz-Aguirre, E. Guillén-Burrieza, Efficiency in the use of solar thermal energy of small membrane desalination systems for decentralized water production, Appl. Energy 130 (2014) 491-499.

[43] G.E. Energy, GE Data Sheet QL833, (2013).

[44] J.H. Lienhard, M.A. Antar, A. Bilton, J. Blanco, G. Zaragoza, Solar desaliantion, Annu. Rev. Heat Transf. 15 (2012) 277-347.

[45] Aquaver, Personal Communication, (2017).

[46] J.A. Andrés-Mañas, A. Ruiz-Aguirre, F.G. Acién, G. Zaragoza, Experimental comparison of two different vacuum multi-effect membrane distillation systems, Presentation in the 2nd International Workshop on Membrane Distillation and Innovating Membrane Operations in Desalination and Water Reuse, Ravello, Italy, 2015.

[47] E. Guillén-Burrieza, A. Ruiz-Aguirre, G. Zaragoza, H.A. Arafat, Membrane fouling and cleaning in long term plant-scale membrane distillation operations, J. Membr Sci. 468 (2014) 360-372.

[48] E. Guillen-Burrieza, R. Thomas, B. Mansoor, D. Johnson, N. Hilal, H. Arafat, Effect of dry-out on the fouling of PVDF and PTFE membranes under conditions simulating intermittent seawater membrane distillation (SWMD), J. Membr. Sci. 438 (2013) 126-139. 